Research Paper

\title{
Anti-inflammatory Effects of Sinomenium Acutum Extract On Endotoxin-induced Uveitis in Lewis Rats
}

\author{
Tae Wan Kim ${ }^{1,2}$, Jeong Mo Han², Young Keun Han ${ }^{1 凶}$, Hokyung Chung ${ }^{1}$ \\ 1. Department of Ophthalmology, Seoul Metropolitan Government Seoul National University Boramae Medical Center, Seoul, Korea \\ 2. Department of Ophthalmology, Seoul National University College of Medicine, Seoul, Korea \\ $\triangle$ Corresponding author: Young Keun Han, MD, PhD, Phone: 82-2-870-2411, Fax: 82-2-831-2826; E-mail: eye129@paran.com \\ ( ) Ivyspring International Publisher. This is an open access article distributed under the terms of the Creative Commons Attribution (CC BY-NC) license \\ (https://creativecommons.org/licenses/by-nc/4.0/). See http://ivyspring.com/terms for full terms and conditions.
}

Received: 2018.01.09; Accepted: 2018.04.27; Published: 2018.05.22

\begin{abstract}
Purpose: Recent studies have reported the anti-inflammatory effect of Sinomenium acutum. We investigated the anti-inflammatory effect of sinomenine on endotoxin-induced uveitis in a rat model. Methods: Endotoxin-induced uveitis was induced in rat by lipopolysaccharide (LPS) immunization. Sinomenine $(50 \mathrm{mg} / \mathrm{kg}$ and $100 \mathrm{mg} / \mathrm{kg}$ ) was administered at 30 minutes before, 6 hours and 12 hours after LPS immunization. Clinical and histological severity was evaluated. Protein concentration and levels of tumor necrosis factor (TNF)- $\alpha$ and prostaglandin (PG)-E2 in aqueous humor were measured. Expression of activated Nuclear factor (NF)-KB p65 in ciliary body was also observed.

Results: Clinical and histological severities were significantly milder in sinomenine-treated rat than in controls $(P<0.001)$. Sinomenine suppressed protein leakage and down-regulated the production of TNF- $\alpha$ and PG-E2 in a dose-dependent manner. Sinomenine treatment suppressed the translocation of the NF-KB p65 subunit into the nuclei.

Conclusion: Systemic administration of sinomenine suppressed the inflammation of ocular tissues. These findings suggest that sinomenine could be a novel therapeutic agent for the control of endogenous ocular inflammatory disease.
\end{abstract}

Key words: endotoxin-induced uveitis; NF-кB; PG-E2; Sinomenium acutum; TNF-a

\section{Introduction}

Uveitis refers to any intraocular inflammation. Anterior uveitis, involving the iris or ciliary body or both, is the most common type of uveitis. Anterior uveitis is reported in a range of $28.5 \%$ to $72 \%$ of uveitis patients in various studies [1-3]. Topical or systemic corticosteroids remain the mainstay of the management of patients with anterior uveitis, but the effect is usually transient. Treatments must be repeated in recurrent and chronic uveitis although the side effects of cataracts and raised intraocular pressure increase in frequency. Currently, no promising therapeutics except corticosteroid is available in the treatment of anterior uveitis.

The mechanisms responsible for anterior uveitis remain unknown. However, recent evidence suggests that $\mathrm{T}$ lymphocytes play an important role in uveitis $[4,5]$. Pathogenic effector $\mathrm{T}$ cells in anterior uveitis are
T helper type 1 (Th1) cells, and they produce some cytokines such as interferon (IFN) $-\gamma$ and interleukin (IL)-2 to recruit inflammatory cells. Some cytokines such as tumor necrosis factor (TNF), IL-1, IL-2, IL-6, and IFN- $\gamma$ have been shown to induce inflammation in experimental animals after intraocular injection.

Endotoxin-induced uveitis (EIU) is an animal model for acute anterior uveitis in humans, first reported by Rosenbaum, which is induced by injection of endotoxin, the lipopolysaccharide (LPS) component of the Gram-negative bacterial cell wall [6, 7]. Observation of the inflammatory reaction in EIU showed that cellular infiltration and protein leakage reaches the maximal point at 24 hours after LPS injection [7]. Elevation of cytokines such as TNF-a, IL-6, monocyte chemoattractant protein (MCP)-1, and macrophage inflammatory protein (MIP)-2 were 
concordant with maximal reaction of EIU $[6,7]$. Other inflammatory mediators such as nitric oxide (NO) and prostaglandin (PG)-E2 are also involved in EIU [8-12].

Recent work has identified a potential treatment for inflammation, Sinomenine (SIN). It is a bioactive alkaloid extracted from the Chinese medicinal plant, Sinomenium acutum. Chinese doctors have begun using this extract to treat rheumatoid arthritis. Previous studies revealed that SIN has an inhibitory effect on lymphocytes proliferation in vitro [13] and a therapeutic effect on adjuvant arthritis, antigeninduced arthritis in rats, and autoimmune encephalomyelitis in rats $[14,15]$. Researchers have proposed that this anti-inflammatory effect of SIN resulted from inhibiting the expression of cytokines, such as TNF-a and IFN- $\gamma$ in the autoimmune encephalomyelitis model and autoimmune arthritis [14, 16]. Furthermore SIN has suppressive effects on both Th1 and Th2 immune responses, but in mice the Th1 response is more suppressed by SIN compared to the Th2 response in mice $[17,18]$.

From this background, we hypothesized that SIN may have an anti-inflammatory effect in the EIU model of rats. The degree of the inflammation was clinically and histopathologically assessed 24 hours after the LPS injection. The total protein concentration, and the levels of TNF- $\alpha$ and PG-E2 in the aqueous humor were measured. The results indicate that SIN shows a dose-dependent anti-inflammatory effect on EIU, suggesting that SIN has a beneficial effect for the control of endogenous ocular inflammatory diseases.

\section{Methods}

\section{Experimental animals}

Eight-week-old male Lewis rats (180 220g) purchased from Oriental Bio (Seoul, Korea) were used in this study. Different groups of rats were created for the experimental design: the experimental group was treated with SIN $50 \mathrm{mg} / \mathrm{Kg}$ and SIN $100 \mathrm{mg} / \mathrm{Kg}$ (Sinomenine hydrochloride, Tocris, St. Louis, MO), the negative control group with its vehicle, phosphate-buffered saline (PBS) and the positive control group with $1 \mathrm{mg} / \mathrm{kg}$ dexamethasone 30 minutes before, simultaneously with and 30 minutes after LPS injection. Ten male Lewis rats were allocated to each group. This animal study was conducted in accordance with guidelines of the ARVO Statement for Use of Animals in Ophthalmic and Vision Research and approval of the Institutional Animal Care and Use Committees (IACUC) of the Biomedical Research Institute at the Seoul National University Hospital (IACUC number: 10-0166).

\section{EIU induction}

EIU was induced by injection into the foodpad of 200ug (100ug for each footpad) LPS from Salmonella typhrimurium (Sigma-Aldrich, St Louis, MO) that had been diluted in $0.2 \mathrm{~mL}$ of PBS. During all procedures, including examination and photography, rats were anesthetized with a 1:1 ketamine hydrochloride (Phoenix Pharmaceutical, St. Joseph, MO): xylazine hydrochloride (Phoenix Pharmaceutical) mixture (1 $\mathrm{mL} / \mathrm{kg}$ ) that was administered intramuscularly and all efforts were made to minimize suffering.

\section{Administration of Sinomenine}

The sinomenine hydrochloride was dissolved in PBS for use in vivo tests. From the day of immunization, rats were treated intraperitoneally with SIN at 30 minutes before, 6 hours and 12 hours after LPS immunization. In addition, to evaluate the dose-response fashion, the experimental group was treated by two different doses of SIN, $50 \mathrm{mg} / \mathrm{kg}$ and $100 \mathrm{mg} / \mathrm{kg}$. Negative control group was treated with only its vehicle, PBS.

\section{EIU evaluation}

The severity of the intraocular inflammation was evaluated clinically and histologically. The degree of the anterior uveitis was clinically assessed 24 hours after the LPS injection. The severity of the intraocular inflammation was graded from 0 (no disease) to 4 (severe disease), as described previously [11]. All eyes were examined with a binocular microscope and then scored clinically on the base of vascular engorgement, pupillary signs, and haziness of anterior chamber.

For infiltrating cell counting, the aqueous humor sample was suspended in an equal amount of Türk stain solution (Merck, Germany), and the cells were counted with a hemocytometer under a light microscope. The number of cells per field (equivalent of $0.1 \mathrm{\mu l}$ ) was manually counted, and the results of four fields from each sample were averaged to calculate the number of cells per microliter.

\section{Protein concentration and Levels of TNF- $\alpha$ and PG-E2 in aqueous humor}

At 24 hours after LPS injection, the rats were euthanatized, and the aqueous humor was collected immediately from both eyes by an anterior chamber puncture (10 15 $\mu \mathrm{L} /$ rat) using a 30-gauge needle under the surgical microscope. The aqueous humor was pooled separately in each group.

The total protein concentration in the aqueous humor samples was measured with a bicinchoninic acid protein assay kit (Pierce, Rockfold, IL). The aqueous humor samples were stored in ice water until testing, and total protein concentrations were 
measured on the day of sample collection.

The levels of TNF-a and PG-E2 in the aqueous humor were assessed with a commercially available ELISA kit (both, R\&D Systems, Minneapolis, MN) according to the manufacturer's instructions. The ELISA assay was performed in duplicate.

\section{Immunohistochemical studies for NF-KB}

We analyzed, by immunohistochemical methods, expression of activated NF- $\mathrm{kB}$ in ciliary body of rats with EIU. At 3 hours after LPS injection, rats were anesthetized, and the eyes were fixed by an intracardiac perfusion of $4 \%$ paraformaldehyde in 0.1 $\mathrm{M}$ PBS. The eyes were enucleated and immersed in the same fixative for 12 hours and embedded in paraffin. Next, 5- $\mu$ m sagittal sections were cut near the ciliary body. Sections were dewaxed with xylene and rehydrated with ethanol. Antigen retrieval was performed by heating sections in a microwave oven. The sections were rinsed in PBS twice and incubated with normal goat serum and then when with phospho-p65 (Ser311) (1:50; Santa Cruz Biotechnology, Santa Cruz, CA). Binding of the primary antisera was localized with Alexa Fluor 555 goat anti-rabbit IgG (1:600; Molecular Probes, Eugene, OR). Nuclei were then stained with PBS containing DAPI (Invitrogen, Eugene, OR) for 5 minutes. The sections were examined by laser scanning confocal microscopy (LSM 510 META, Carl Zeiss, Germany). Within each sample, two areas were randomly photographed, and the number of activated NF- $\kappa$ B-positive cells was counted. The results of the two areas were averaged for each sample and in each group. This analysis was performed in the four eyes of two rats in each group.

\section{Statistical analysis}

Data was expressed as the mean \pm standard deviation (SD). The Bonferroni test was used as a post hoc comparison to compare the four treatment groups after one-way ANOVA. $\mathrm{P}<.05$ was considered to be statistically significant. Statistical analyses were performed using SPSS for Windows version 18.0 (SPSS Inc, Chicago, Illinois, USA).

\section{Results}

\section{SIN treatment ameliorates EIU}

Severe inflammation was found in the anterior segment of negative control rats at 24 hours after LPS administration. Obvious iridal hyperemia and exudative material could be observed in the anterior segment with slit lamp examination (Fig 1). Clinical scores were $3.75 \pm 0.46,2.12 \pm 0.64,1.38 \pm 0.74$, and $1.13 \pm 0.35$ in negative control group, SIN $50 \mathrm{mg} / \mathrm{kg}$, SIN $100 \mathrm{mg} / \mathrm{kg}$, and positive control group, respectively. Significant reductions of inflammation were observed in eyes treated with $50 \mathrm{mg} / \mathrm{kg}, 100$ $\mathrm{mg} / \mathrm{kg}$ of SIN as well as $1 \mathrm{mg} / \mathrm{kg}$ of dexamethasone compared to those in eyes treated with vehicle only (Fig 2).

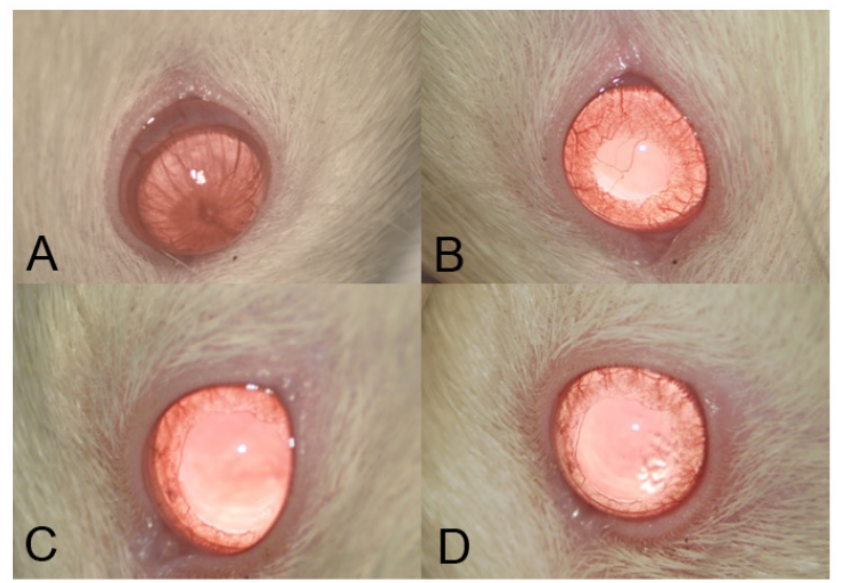

Figure 1. Clinical evaluation shows that sinomenine (SIN) prevents the inflammation in endotoxin-induced uveitis (EIU) in the iris and conjunctiva of rats. ElU-induced rats were treated with a vehicle, phosphate-buffered saline (PBS) (A), low-dose sinomenine (SIN) $(50 \mathrm{mg} / \mathrm{kg}$, B), high-dose SIN $(100 \mathrm{mg} / \mathrm{kg}$, C), and dexamethasone $(1 \mathrm{mg} / \mathrm{kg})$, D). Results were given as mean \pm SD. Note that the eyes of rats treated with PBS had severe inflammation, conjunctival injection, iris vascular engorgement, miosis, and exudative material at anterior chamber. In the eyes of rats treated with SIN $50 \mathrm{mg} / \mathrm{kg}$, moderate inflammatory reaction was showed. Both eyes of rats treated with $\mathrm{SIN} 100 \mathrm{mg} / \mathrm{kg}$ and dexamethasone $1 \mathrm{mg} / \mathrm{kg}$ showed mild inflammatory reaction.

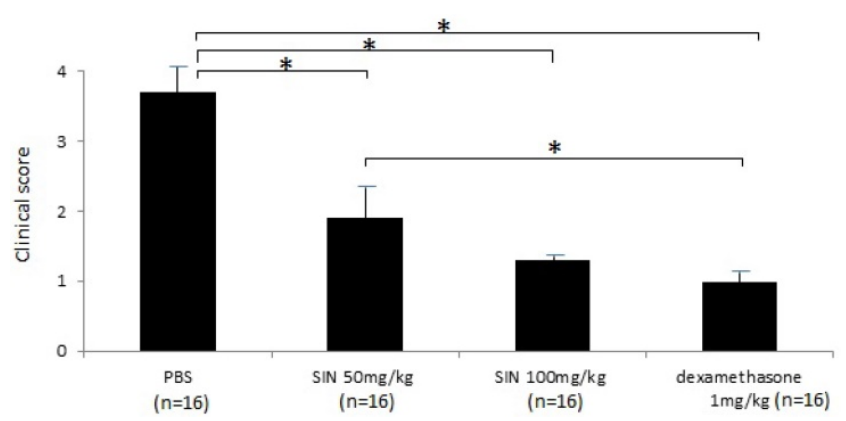

Figure 2. Sinomenine (SIN) prevents the inflammation of endotoxin-induced uveitis (EIU) in rats. The clinical score of EIU in Lewis rats eyes in the absence and presence of SIN was determined at 24 hours after LPS injection with a slit lamp microscope. Results were given as mean $\pm \mathrm{SD}$. Note that the eyes of rats treated with PBS had higher score than those of rats treated with SIN $50 \mathrm{mg} / \mathrm{kg}$, $100 \mathrm{mg} / \mathrm{kg}$ and dexamethasone $1 \mathrm{mg} / \mathrm{kg}$. Ocular inflammation was significantly decreased in SIN-treated rats compared to untreated rats. $* P<0.05$, one-way ANOVA followed by a Bonferroni post hoc test

Histopathologic analysis also revealed a prominent cyclitis characterized by macrophages, polymorphonuclear cells and lymphocytes in the ciliary body and vitreous. Representative $\mathrm{H} \& \mathrm{E}$ histology of SIN-treated and -untreated rats is shown in Fig 3. In negative control mice, inflammatory cells were found in the ciliary body (Fig 3A, 3C). Dexamethasone-treated rats showed no inflammatory cells in the ciliary body (Fig 3B, 3D). Ciliary body collected from rats treated with $50 \mathrm{mg} / \mathrm{kg}$ SIN 
showed mild cell infiltration without structural damage. Ciliary body collected from rats treated with $100 \mathrm{mg} / \mathrm{kg}$ SIN showed almost normal histology (Fig $3 \mathrm{E}$ and $3 \mathrm{~F}$ ).

In the negative control group, the number of inflammatory cells in aqueous humor at 24 hours after LPS administration was $29.5 \pm 7.55 \times 10^{5}$ cells $/ \mathrm{mL}(\mathrm{n}=$ 16). The numbers of inflammatory cells in aqueous humor were $16.5 \pm 5.0 \times 10^{5}$ cells $/ \mathrm{mL}, 10.0 \pm 3.7 \times 10^{5}$ cells $/ \mathrm{mL}$, and $4.3 \pm 2.2 \times 10^{5}$ cells $/ \mathrm{mL}$ in SIN 50 $\mathrm{mg} / \mathrm{kg}$, SIN $100 \mathrm{mg} / \mathrm{kg}$, and positive control group (Fig 4). Treatment with 50 and $100 \mathrm{mg} / \mathrm{kg}$ SIN significantly reduced the number of inflammatory cells in comparison with a negative control group $(\mathrm{P}=$ $0.043, \mathrm{P}=0.021$, respectively). The effect of $100 \mathrm{mg} / \mathrm{kg}$ SIN on the number of cells in the aqueous humor was lower but not statistically significant than the effect of

$1 \mathrm{mg} / \mathrm{kg}$ dexamethasone $(\mathrm{P}=0.059)$. In addition, there were no systemic adverse events including weight loss, hair loss, or sudden death.

\section{Effect of SIN on protein concentration and TNF- $\alpha / P G-E 2$ in aqueous humor}

Protein concentrations were $97.6 \pm 15.6 \mathrm{mg} / \mathrm{mL}$, $38.7 \pm 3.5 \mathrm{mg} / \mathrm{mL}, 15.8 \pm 2.4 \mathrm{mg} / \mathrm{mL}$, and $6.1 \pm 1.4$ $\mathrm{mg} / \mathrm{mL}$ in negative control, SIN $50 \mathrm{mg} / \mathrm{kg}$, SIN $100 \mathrm{mg} / \mathrm{kg}$, and positive control group (Fig 5). Protein concentration in aqueous humor was significantly higher in negative control group than in SIN 50 $\mathrm{mg} / \mathrm{kg}, 100 \mathrm{mg} / \mathrm{kg}$ and dexamethasone $1 \mathrm{mg} / \mathrm{kg}$ group. Protein concentration in aqueous humor showed the anti-inflammatory effect of SIN.

Considerable production of TNF- $a$ and PGE2 in the aqueous humor was seen in the negative control group. SIN treatment also significantly reduced their concentrations in aqueous humor

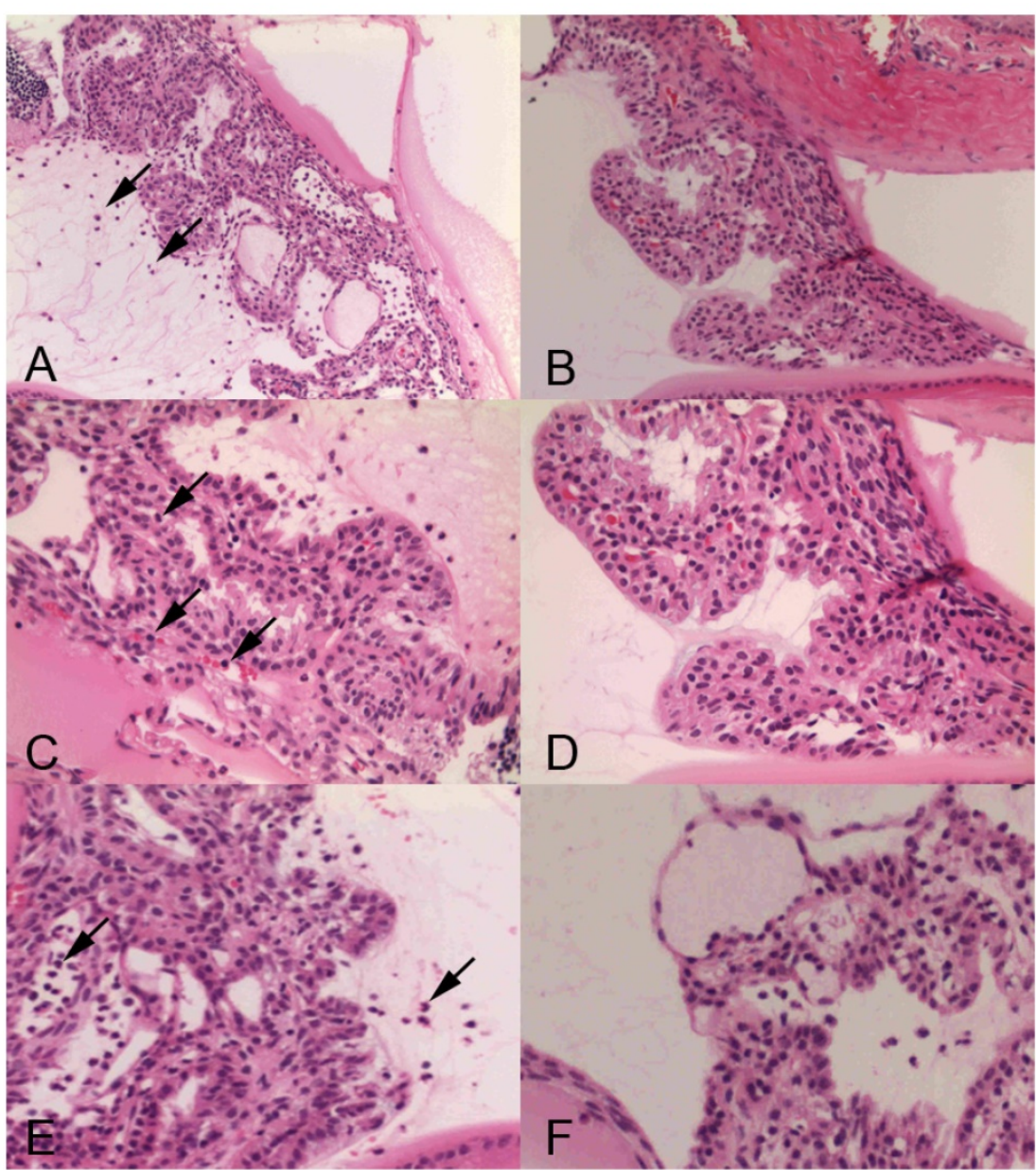

Figure 3. Representative histopathology in ciliary body of Lewis rats' eyes of endotoxin-induced uveitis in the absence and presence of sinomenine (SIN). Inflammatory cells are indicated as arrow. Rats with endotoxin-induced uveitis were treated with phosphate-buffered saline (PBS) (A) and $1 \mathrm{mg} / \mathrm{kg}$ of dexamethasone (B) (X200 magnification). Higher magnification (X400 magnification) of ciliary body in rats treated with PBS (C) and $1 \mathrm{mg} / \mathrm{kg}$ of dexamethasone (D). Severe inflammatory cells were observed in the PBS-treated rats (A, C). Higher magnification (X400 magnification) of ciliary body in rats treated with of SIN (E) and $100 \mathrm{mg} / \mathrm{kg}$ of SIN (F). Ciliary body collected from rats treated with $50 \mathrm{mg} / \mathrm{kg}$ SIN showed mild cell infiltration without structural damage. Ciliary body collected from rats treated with $100 \mathrm{mg} / \mathrm{kg}$ SIN showed almost normal histology. Results were given as mean \pm SD with a dose-dependent fashion. (Fig $6 \mathrm{~A}, 6 \mathrm{~B})$

\section{Immunohistochemistry of NF-KB p65}

Activated NF-кB p65 immunoreactivity was strongly expressed in the iris-ciliary body. In contrast, the number of activated NF- $\kappa$ B-positive cells were lower in the iris-ciliary body of rats treated with SIN. Representative confocal microphotographs of ciliary body immunostained with antibodies against NF-KB p65 of SIN-treated and -untreated rats is shown in Fig 7. Considerable expression of activated NF-kB p65 was observed in the nuclei of the iris-ciliary body of EIU rats treated with vehicle alone (Fig. 7A). Only a few NF-kB p65-positive nuclei were detected in SIN- and dexamethasone-treated EIU rats (Fig. 7B, 7C and 7D). Mean proportion of activated NF-kB-positive cells in the iris-ciliary body of control-EIU rats was $34.5 \pm$ $3.8 \%$, whereas that in $50 \mathrm{mg} / \mathrm{kg}$ or $100 \mathrm{mg} / \mathrm{kg}$ SIN-treated EAU mice was $17.0 \pm 2.1 \%$ or $14.6 \pm 2.8 \%$, respectively (Fig. 8). The proportion of activated NF-KB-positive cells was significantly lower in EIU rats treated with 50 and $100 \mathrm{mg} / \mathrm{kg}$ SIN than that in control rats $(\mathrm{P}=0.016, \mathrm{P}=$ 0.010, respectively). 


\section{Discussion}

Data from our study demonstrated that SIN has an anti-inflammatory effect both clinically and histopathologically on intraocular inflammation in a dose-response fashion. Treatment with SIN significantly decreased total protein concentration, and the levels of TNF- $\alpha$ and PG-E2 in the aqueous humor, and decreased the number of activated NF-KB-positive cells. An intraperitoneal administration of SIN at the time of immunization significantly decreased the protein leakage and the inflammatory cytokines, markedly repressed ocular inflammation, and subsequently prevented damage in the eyes of rats with EIU.

To elucidate the anti-inflammatory mechanism of SIN, we measured the NF-KB intranuclear positive rate. The activation of NF- $\mathrm{kB}$ plays a pivotal role in the pathogenesis of EIU and the NF- $\mathrm{kB}$ inhibitor decreased inflammation in uveitis $[8,19,20]$. After phosphorylation, the dissociation of $\mathrm{I}-\kappa \mathrm{B}$ was facilitated, thus inducing the translocation of NF-KB which acts as a transcription factor. We showed that increased NF-kB activity in EIU correlates with clinical and histological grading of inflammation and that NF-KB activity was decreased in SIN-treated group. Even though exact pathways for the anti-inflammatory effect of SIN are still unknown, the possible therapeutic mechanism of SIN in inflammation can be by inhibition of NF-KB activation. Our data are consistent with previous reports that the inhibition of NF-KB may reverse the inflammatory process in other autoimmune diseases $[21,22]$. Our results were also consistent with previous reports that SIN has been used to treat the inflammatory diseases including autoimmune encephalitis and arthritis in animal models [15, 16, 18]. While this is encouraging, additional research is necessary to further reveal the exact mechanism by which SIN suppressed the intraocular inflammation.

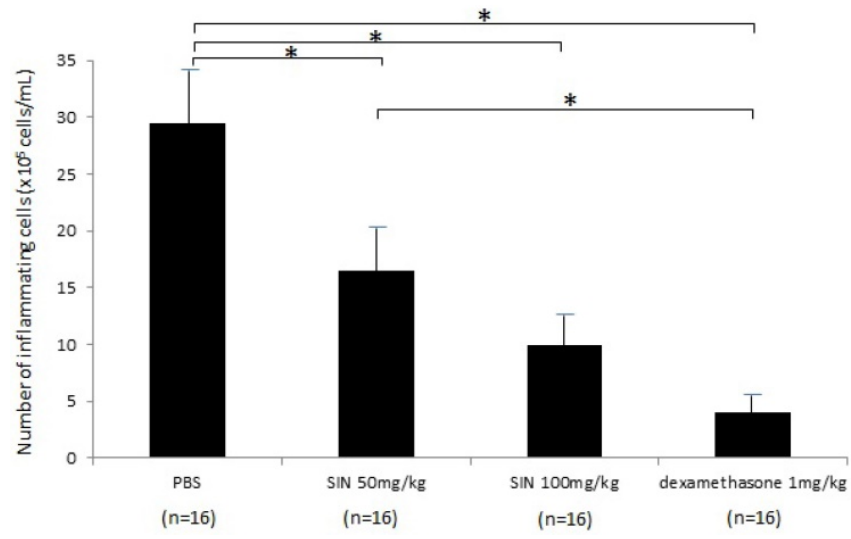

Figure 4. A diagram of histopathologic evaluation in rats with endotoxin-induced uveitis. For infiltrating cell counting, the aqueous humor sample was suspended in an equal amount of Türk stain solution (Merck, Germany), and the cells were counted with a hemocytometer under a light microscope. The number of cells per field (equivalent of $0.1 \mu \mathrm{l}$ ) was manually counted, and the results of four fields from each sample were averaged to calculate the number of cells per microliter. A significant reduction in inflammatory cells was observed in the aqueous humor of rats treated with $50 \mathrm{mg} / \mathrm{kg}$ and $100 \mathrm{mg} / \mathrm{kg}$ of sinomenine (SIN). Results are expressed as mean \pm SD. $* P<0.05$, one-way ANOVA followed by a Bonferroni post hoc test

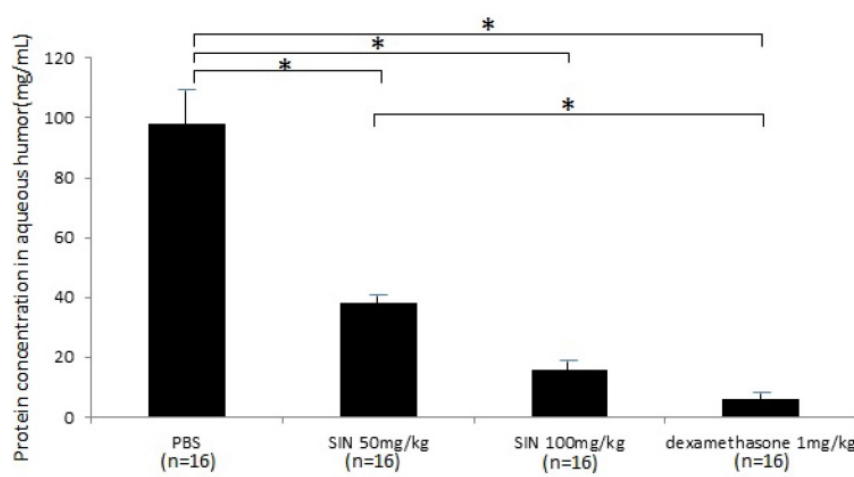

Figure 5. Effect of sinomenine (SIN) on protein level in aqueous humor collected 24 hours after the induction of endotoxin-induced uveitis. Protein leak was decreased in rats treated with SIN $50 \mathrm{mg} / \mathrm{kg}$ and $100 \mathrm{mg} / \mathrm{kg}$. Results are given as mean $\pm \mathrm{SD}$. $* P<0.05$, one-way ANOVA followed by a Bonferroni post hoc test
(A)

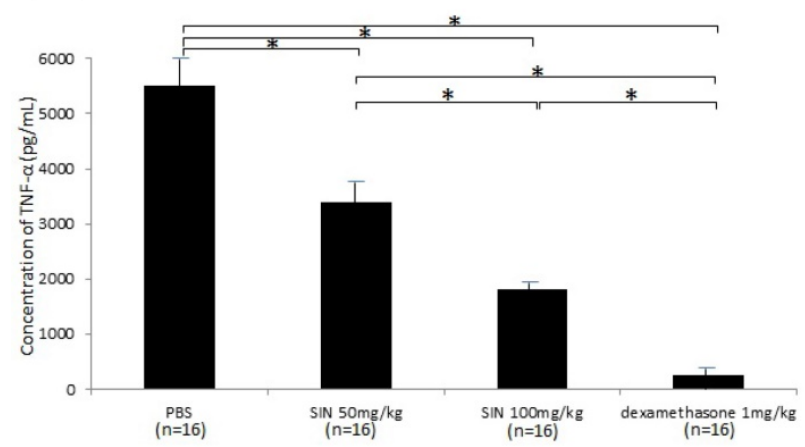

(B)

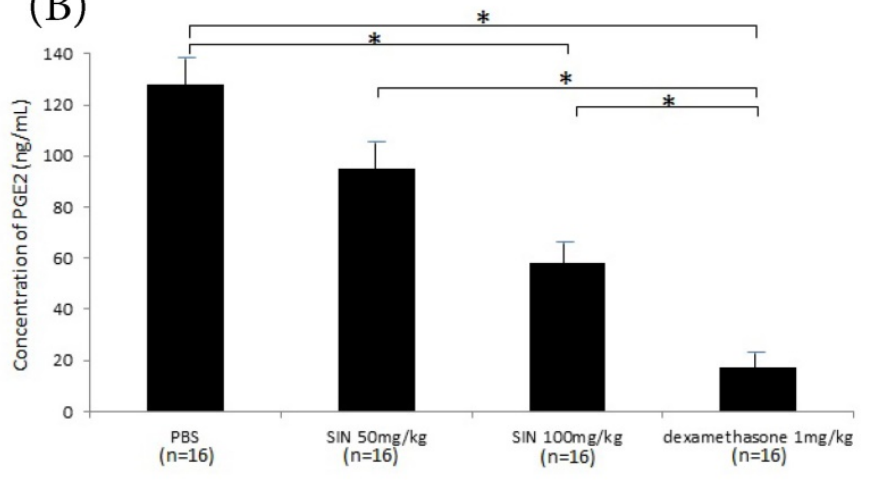

Figure 6. Effect of sinomenine (SIN) on tumor necrosis factor (TNF)- $\alpha$ (A) and prostaglandin (PG)-E2 (B) in aqueous humor collected 24 hours after the induction of endotoxin-induced uveitis. The level of TNF- $\alpha$ and PG-E2 was decreased in rats treated with SIN 50mg/kg and $100 \mathrm{mg} / \mathrm{kg}$ in a dose-dependent manner. Results are given as mean mean $\pm \mathrm{SD}$. $* P<0.05$, one-way ANOVA followed by a Bonferroni post hoc test 


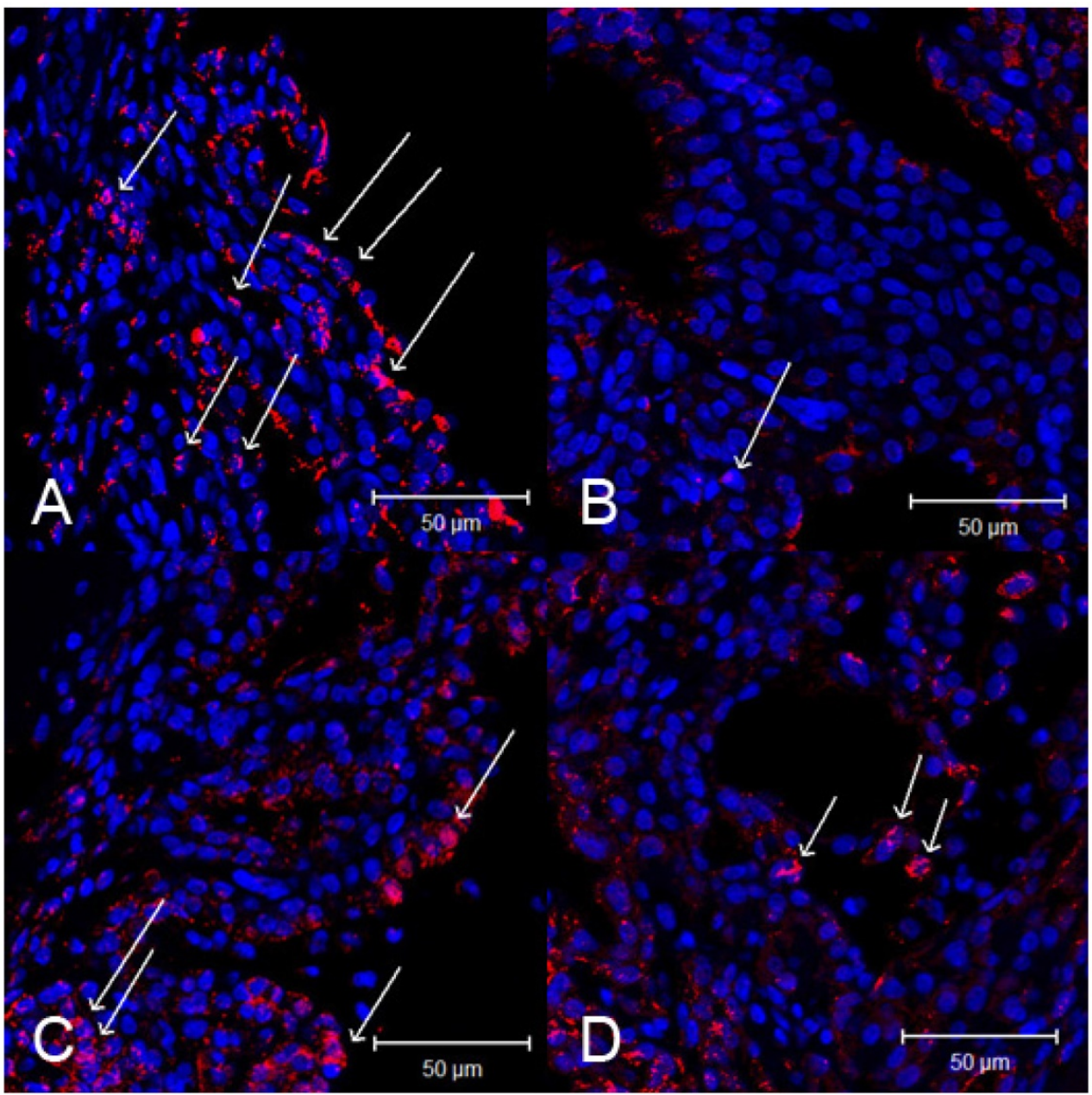

Figure 7. Effect of sinomenine (SIN) on nuclear factor (NF)-KB p65 activation in the ciliary body 3 hours after the induction of endotoxin-induced uveitis (EIU). Confocal microphotographs of ciliary body immunostained with antibodies against NF-KB p65 (red) and nuclei (blue). Activated NF-KB is indicated as arrows. Rats with EIU were treated with phosphate-buffered saline (PBS) (A), $1 \mathrm{mg} / \mathrm{kg}$ of dexamethasone (B), $50 \mathrm{mg} / \mathrm{kg}$ of SIN (C), and $100 \mathrm{mg} / \mathrm{kg}$ of SIN (D). Magnification $\times 400$. Results were given as mean $\pm S D$.

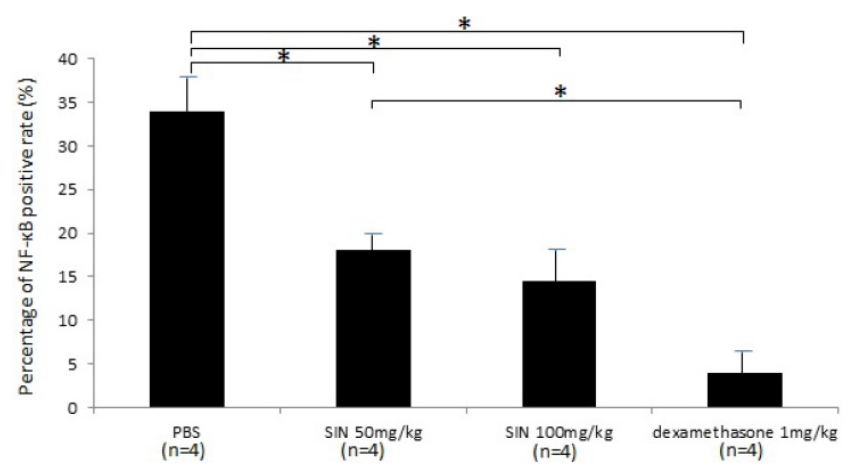

Figure 8. Effect of sinomenine (SIN) on nuclear factor (NF)-KB positive rate. The proportion of activated NF-kB-positive cells was significantly lower in endotoxin-induced uveitis (EIU) rats treated with SIN than in those with phosphate-buffered saline (PBS). Data are the mean \pm SD. $* P<0.05$, one-way ANOVA followed by a Bonferroni post hoc test

Using a plant extract as a monotherapy for ocular inflammatory diseases is highly controversial. Furthermore, EIU rat model does not perfectly mimic uveitis in humans. EIU is acute and self-limited.
Nevertheless, there are several reasons why the effect of SIN on EIU deserves attention. First, the short-term effects were quite promising although the long-term effects must be confirmed. Second, current therapeutic strategies for ocular inflammatory diseases involve the long-term use of corticosteroid or immunosuppressants. Repeated use of corticosteroids carries the risk of serious ocular adverse events such as cataract, increased intraocular pressure, and glaucoma. Therefore, a novel drug with a good safety profile could provide an alternative approach for ocular inflammatory diseases. SIN has a good safety profile with its use in traditional medicine and has shown no side effects in our study. In addition, SIN and corticosteroid could have synergistic properties and, together, have the potential to reduce the risks related to long-term use of corticosteroids. The concomitant therapy with corticosteroids and SIN would further studies.

In summary, this study indicates that SIN shows a dose-dependent anti-inflammatory effect on EIU. A 
possible mechanism for the effect of SIN may depend on its ability to inhibit the activation of NF-KB-related pro-inflammatory cascade. To the best of our knowledge, there have been no reports on the effect of SIN on uveitis. It could be more effective with increased doses. We suggest that SIN is a potential candidate drug for treating ocular inflammatory diseases.

\section{Acknowledgment}

This research was funded by the Clinical Research Program of Seoul Metropolitan Government - Seoul National University BORAMAE Medical Center (03-2010-12).

\section{Competing Interests}

The authors have declared that no competing interest exists.

\section{References}

1. Bodaghi B, Cassoux N, Wechsler B, Hannouche D, Fardeau C, Papo T, et al. Chronic severe uveitis: etiology and visual outcome in 927 patients from a single center. Medicine. 2001; 80: 263-70.

2. Singh R, Gupta V, Gupta A. Pattern of uveitis in a referral eye clinic in north India. Indian J Ophthalmol. 2004; 52: 121-5.

3. Acharya NR, Tham VM, Esterberg E, Borkar DS, Parker JV, Vinoya AC, et al. Incidence and prevalence of uveitis: results from the Pacific Ocular Inflammation Study. JAMA ophthalmol. 2013; 131: 1405-12.

4. Luger D, Silver PB, Tang J, Cua D, Chen Z, Iwakura Y, et al. Either a Th17 or a Th1 effector response can drive autoimmunity: conditions of disease induction affect dominant effector category. J Exp Med. 2008; 205: 799-810.

5. Chong WP, Horai R, Mattapallil MJ, Silver PB, Chen J, Zhou R, et al. IL-27p28 inhibits central nervous system autoimmunity by concurrently antagonizing Th1 and Th17 responses. J Autoimmun. 2014; 50: 12-22.

6. Planck SR, Huang XN, Robertson JE, Rosenbaum JT. Cytokine mRNA levels in rat ocular tissues after systemic endotoxin treatment. Invest Ophthalmol Vis Sci. 1994; 35: 924-30.

7. de Vos AF, van Haren MA, Verhagen C, Hoekzema R, Kijlstra A. Kinetics of intraocular tumor necrosis factor and interleukin- 6 in endotoxin-induced uveitis in the rat. Invest Ophthalmol Vis Sci. 1994; 35: 1100-6.

8. Kracht M, Saklatvala J. Transcriptional and post-transcriptional control of gene expression in inflammation. Cytokine. 2002; 20: 91-106.

9. Jacquemin E, de Kozak Y, Thillaye B, Courtois Y, Goureau O. Expression of inducible nitric oxide synthase in the eye from endotoxin-induced uveitis rats. Invest Ophthalmol Vis Sci. 1996; 37: 1187-96.

10. Bellot JL, Palmero M, Garcia-Cabanes C, Espi R, Hariton C, Orts A. Additive effect of nitric oxide and prostaglandin-E2 synthesis inhibitors in endotoxin-induced uveitis in the rabbit. Inflamm Res. 1996; 45: 203-8.

11. Ruiz-Moreno JM, Thillaye B, de Kozak Y. Retino-choroidal changes in endotoxin-induced uveitis in the rat. Ophthalmic Res. 1992: 24:162-8.

12. Sato K, Mihara Y, Kanai K, Yamashita Y, Kimura Y, Itoh N. Tyrosol ameliorates lipopolysaccharide-induced ocular inflammation in rats via inhibition of nuclear factor (NF)-kappaB activation. J Vet Med Sci. 2016; 78: 1429-38.

13. Liu L, Buchner E, Beitze D, Schmidt-Weber CB, Kaever V, Emmrich F, et al. Amelioration of rat experimental arthritides by treatment with the alkaloid sinomenine. Int J Immunopharmacol. 1996; 18: 529-43.

14. Zeng $Y$, Gu B, Ji X, Ding X, Song C, Wu F. Sinomenine, an antirheumatic alkaloid, ameliorates clinical signs of disease in the Lewis rat model of acute experimental autoimmune encephalolmyelitis. Biol Pharm Bull. 2007; 30: 1438-44.

15. Liu L, Resch K, Kaever V. Inhibition of lymphocyte proliferation by the anti-arthritic drug sinomenine. Int J Immunopharmacol. 1994; 16: 685-91.

16. Zhou $\mathrm{H}$, Wong YF, Wang J, Cai X, Liu L. Sinomenine ameliorates arthritis via MMPs, TIMPs, and cytokines in rats. Biochem Biophys Res Commun. 2008; 376: 352-7.

17. Feng $\mathrm{H}$, Yamaki $\mathrm{K}$, Takano $\mathrm{H}$, Inoue $\mathrm{K}$, Yanagisawa $\mathrm{R}$, Yoshino $\mathrm{S}$. Suppression of Th1 and Th2 immune responses in mice by Sinomenine, an alkaloid extracted from the chinese medicinal plant Sinomenium acutum. Planta Med. 2006; 72: 1383-8.

18. Feng $\mathrm{H}$, Yamaki $\mathrm{K}$, Takano $\mathrm{H}$, Inoue $\mathrm{K}$, Yanagisawa R, Yoshino S. Effect of sinomenine on collagen-induced arthritis in mice. Autoimmunity. 2007; 40: $532-9$.
19. Kitamei H, Iwabuchi K, Namba K, Yoshida K, Yanagawa Y, Kitaichi N, et al. Amelioration of experimental autoimmune uveoretinitis (EAU) with an inhibitor of nuclear factor-kappaB (NF-kappaB), pyrrolidine dithiocarbamate. J Leukoc Biol. 2006; 79: 1193-201.

20. Klaska IP, Muckersie E, Martin-Granados C, Christofi M, Forrester JV. Lipopolysaccharide-primed heterotolerant dendritic cells suppress experimental autoimmune uveoretinitis by multiple mechanisms. Immunology. 2017; 150: 364-77.

21. Iwata D, Kitaichi N, Miyazaki A, Iwabuchi K, Yoshida K, Namba K, et al. Amelioration of experimental autoimmune uveoretinitis with nuclear factor-\{kappa\}B Inhibitor dehydroxy methyl epoxyquinomicin in mice. Invest Ophthalmol Vis Sci. 2010; 51: 2077-84

22. Okamoto T, Ozawa Y, Kamoshita M, Osada H, Toda E, Kurihara T, et al. The neuroprotective effect of rapamycin as a modulator of the mTOR-NF-kB axis during retinal inflammation. PloS one. 2016; 11: e0146517. 